\title{
DIE CHILIASME IN DIE GEREFORMEERDE KERK EN 'N ANTWOORD DAAROP
}

\section{Enkele algemene opmerkings}

1.1. Die chiliasme is 'n leer wat baie geliefd is by baie sektes. Tog moet ons oppas om alle chiliastiese neigings onder een hoof saam te vat en te sê dat almal sektaries is! Die Jehowa-getuies is byvoorbeeld ook chiliasties gesind maar hulle leer kan maklik op dogmatiese punte uitmekaar getrek word. By die chiliasme in die Gereformeerde Kerk is dit heeltemal 'n ander saak. Daar is die vredetyd nie 'n tyd vir verbetering op grond van 'n algemene versoeningsleer nie.

1.2. Vervolgens duik die chiliasme op as 'n handige sleutel om bepaalde skrifgedeeltes te verklaar by mense wat op eie houtjie sit en worstel met sommige profesië en veral die boek Openbaring.

1.3. Ten opsigte van die chiliasme as gedagterigting by Gereformeerdes moet ons hoofsaaklik teruggaan na die optrede van ds. S. J. du Toit en later ook die optrede van sy seun, ds. C. W. M. du Toit. Die ontstaan van die Gereformeerde Kerke onder die Kruis is by u almal goed bekend en ek gaan nie verder daarop in nie.

1.4. Ds. S. J. du Toit het in sy bediening baie aandag gegee aan die profesië en baie geskrifte in die verband gepubliseer waarop sy aanhangers tot vandag nog terugkom. Sy seun, ds. C. W. M. du Toit, het in die rigting van sy vader verder beweeg met sy optrede en ook sy publikasies. Veral vanweë die apologetiese strekking van veral lg. se geskrifte maar waarop daar in Gereformeerde kringe weinig antwoord gegee is, het dié leer baie aan geloofwaardigheid gewen. ${ }^{1}$

Aanvanklik is die chiliasme nie as 'n nuwe leer aangebied nie maar hoofsaaklik as 'n antwoord op vrae wat gewoonlik in die prediking agterweë gebly het en vanweë die verwaarlosing van die profetiese geskrifte in die Bybel. Ds. C. W. M. du Toit is egter die man wat die chiliasme aangebied het as die suiwere eschatologie en het die gereformeerde standpunt oor verskeie aspekte van die eschatologie as dwaling aangedui. ${ }^{2}$ Hierdie wendinr wil ek toeskryf aan meerdere publikasies oor hierdie sake wat gedurende die begin van hierdie eeu en ook later vrygestel is, en waarteen ds. C. W. M. du Toit hom sterk opgestel het. Wat verder nog bygedra het tot die geloofwaardigheid van hierdie leer is die feit dat die Geref. Kerk nie op sinodale vlak 'n uitspraak wou gee oor die chiliasme nie. Dit het ' $n$ indruk gelaat wat goed uitgebuit is.

Vanweë die kortstondige bestaan van die kerkverband van die gereformeerdes onder die kruis, en vanweë die feit dat die chiliasme nie verder amptelik verkondig is nie behalwe deur ds. C. W. M. $\mathrm{du}$ Toit, was die aanhangers van hierdie leer hoofsaaklik aangewys op selfstudie sodat dit vandag moeilik is om die chiliasme as 'n eenvormige leer by lidmate aan te dui. Chiliaste verskil onderling dikwels baie van mekaar. By die voortgaande selfstudie word baie 
gebruik gemaak van artikels en preke uit „Die Getuie” wat weer herdruk is en verskyn het in die gemeenteblad van die V.C.G. (Vrye Christelike Gereformeerde) Kerk te Frankfort. Deur die toedoen van lg. het die aanvanklike publikasie van ds. S. J. du Toit en ds. C. W. M. du Toit nie in die vergetelheid geraak nie. So het in 1971 ook weer 'n herdruk verskyn van ds. S. J. du Toit se „Die onvervulde profesië" van $1878 .{ }^{3}$

In hierdie referaat wil ek my beperk tot die uiterste hoofpunte van die leer en wil daarop 'n antwoord probeer bied. Hierby sal gevolglik sake ongenoem bly wat wel belangrike bakens is in die chiliasme maar wat in wese afleidings bly van 'n basiese vooringenomenheid. Ek beperk my tot hierdie basiese vooringenomenheid. Die antwoord op hierdie leer berus op 'n openbaringshistoriese regstelling van bepaalde sake en verder die tyddsraamwerk soos dit in Openbaring gegee word om sodoende Openb. $20: 1-10$ geplaas te kry.

\section{Kernpunte van die leer}

Die chiliastiese leer wat ons by lidmate aantref, is hoofsaaklik gebaseer op die volgende besware:

2.1. Verwaarlosing van die profetiese gedeeltes in die Skrif (word dikwels in die prediking nie die profetiese gedeeltes meer vir paranetiese doeleindes gebruik en word die vervulling van die profesie - 'n primêre taak van skrifverklaring - nie 'n bietjie op die agtergrond gelaat nie?). Hierdie beswaar is m.i. baie gewigtig.

2.2. Onduidelikheid oor die eschatologie. Volgens hulle het die profesië beslis eschatologiese uitsprake. Aangesien dikwels in die gereformeerde prediking die profesie-verklaring agterweë bly, word die profesië deur hulle geprojekteer na die toekoms en die gereformeerde eschatologie verskaf weinig voldoening aan hierdie leemte wat deur hulle aangevoel word. Dié beswaar is m.i. ook wettig omdat die Openbaringsboek en die hele benadering van die einde in Openbaring in die geref. eschatologie te min verdiskonteer is. Het ons nie die eschatologie te veel verdogmatiseer tot die laaste locus van die dogmatiek sodat in dié opset die verwagting van die kerk, soos so mooi in art. 37, N.G.B. na vore kom, soek geraak het nie? Hierdie leemte in die eschatologie word natuurlik nie net aangevoel deur die chiliaste nie maar deur 'n hele string van moderne teoloë, nl. Moltmann, König, Sölle, ens., om maar 'n paar te noem! 1

2.3. Onduidelikheid ten opsigte van sekere punte van die eschatologie, nl. die posisie van Israel, die antichris en die skepping se toekoms (asof die verlossing in Christus net mens-georiënteerd is terwyl tog ook die skepping met reikhalsende verlange sug, Rom. 8 !). Hierby wil ek volstaan.

\section{Kernpunte sistematies-krities uiteengesit}

3.1. Die profesie en profesie-verklaring

Die profesie voorspel baie dinge in bekende Israel-kategorië. So is daar in Eségiël vanaf hoofstuk 40 voorspellings vir die toekoms 
aangaande die Aäronitiese priesterdiens. Sommige beweer dat in die vredetyd, die herstel van o.a. Israel en Kanaän, hierdie priesterkultus volgens Eségiël heeltemal in ere herstel word. Hierdie siening druis natuurlik lynreg in teen die behandeling van die priesterskap in Hebreërs en die instelling van die nagmaal. Wanneer hierdie profesie egter in Nieu-Testamentiese lig verklaar word o.g.v. byvoorbeeld Hebreërs, wag op die verklaarder gou die beskuldiging van vergeesteliking. Dieselfde probleem duik ook op waar die herstel van die land geprofeteer word, bv. in Jes. 11. Dié aanklag van vergeesteliking kan ek heeltemal begryp want:

3.1.1. die direkte openbaringshistoriese verband t.o.v. profesie en vervulling moet eers aangetoon word;

3.1.2. die Christo-sentriese (Openb. 19:10) van die profesie (nie Christo-monistiese nie want dis die rigting waarin die Christusprediking in die profesieverklaring dikwels op die kansel beweeg!) moet ook duidelik aangetoon word;";

3.1.3. verder moet die O.T.-kategorie waarin geprofeteer word, waar nodig deurbreek word nadat die O.T.-kategorie eers aangetoon is, bv. die Dawidiese koningskap, die Salomoniese vrede, die Aäronitiese priesterkultus, ens., want Christus het in sy volheid dié kategorië vervul en volgemaak. Omdat, na my mening, in ons prediking hierdie sake nie genoegsaam aan die orde kom nie uit vrees om nie met ons kombuiswerk op die tafel te kom en die gemeente daarmee vermoei nie, werk ons inderdaad die probleem van vergeesteliking van die profesie in die hand.

\subsection{Die eschatologie}

Die eschatoloriese aanloop in die O.T., dit wil sê dat bepaalde gedeeltes wel sien op die finale einde van alle dinge, word sekerlik nie genoeg afgehandel wanneer ons net dink in terme van die bergpiek-en-dal kitsoplossing nie. Hiervolgens het die profeet dan sogenaamd vanweë sy beperkte profetiese horison dinge wat in die tyd uitmekaar gespasieer is, as een geheel gesien. Die amper locus classicus is die twyfel van Johannes die Doper in die tronk dat Jesus as die Messias nie die dorsvloer skoonmaak en die byl wat teen die wortel van die bome lê, nie optel en die bome neervel nie. Die tradisionele verklaring van die gedeelte is dat Johannes die Doper dinge wat in die tyd gespasieerd is, as 'n eenheid saamgevat het. Die problematiek raak ook die meeste ,in dié dag" en die „dag van die HERE"-uitsprake in die O.T. Dan redeneer die chilias as volg: die profeet sien die saak as 'n eenheid en daarom is dit ' $n$ letterlike eenheid; by Christus is beide aspekte van die een profesie nog nie letterlik vervul nie, dus lê die volle vervulling nog in die toekoms voor. Hierteenoor meen ek dat ons tog nie te eensydig moet dink oor die eerste koms van Christus nie. Natuurlik moet ons nie in die uiterste van die gerealiseerde eschatologie verval nie. By Christus se eerste koms het reeds eschatologiese tekens in vervulling gegaan, bv. die duisternis op die aarde, die aardbewing, die grafte wat oopgegaan het, ens., hoewel nog nie uitputtend nie. Verder was 
Christus se eerste koms nie net alles goed en genade nie. Die byl lê teen die wortel van die bome. Teen die wortel, dus nie net dooie takke afkap nie maar die bome grondig uitroei! Dis oordeel! Verder die perspektief wat Paulus gee in Rom. 11 op die heiden-sending. Dis tog ' $n$ ingrypende aspek van oordeel by die eerste koms; en verder die middelaarsbede: Vader, vergeef hulle, stel die oordeel uit." Ek dink dat ons met reg meer rekenskap kan gee van die dubbele karakter van die eerste koms van Christus, en dan sal die profesievervulling in Christus meer gestalte kry.

Met ander woorde: die O.T. betrek, vanweë die dubbele karakter van Christus se koms in die vlees, die eschatologie reeds op hierdie gebeure. König dui hier 'n heldere nuwe weg aan as hy sê dat ons in die eschatologie nie net moet dink aan ta eschata nie maar veral aan $H \bar{o}$ Eschatos: die Persoon en koms van Christus is eschatologie, ${ }^{7}$ en dit om dié rede, dat die dubbele kant van die profesie, nl. oordeel en genade, wel grootliks by die eerste koms ter sprake is. As ons só gaan verklaar, sal die betrokke profesie self aanwys wat nog inderdaad onvervuld is en in watter sin onvervuld met inagneming van die deurbraak van die O.T.-kategorie in en deur Christus.

Vanweë die sogenaamde onvervulde profesië, almal Ou-Testamenties-Israel-sentries verstaan, het die gebeure in Palestina vandag baie betekenis met heilshistoriese afmetings vir die chiliaste. Inderdaad kan ons die krisis in die midde-ooste nie sommer van ons afskud nie want dié Jode leef in verharding voort, Rom. 11. Oor hierdie krisis sal ons weer moet dink. ${ }^{8}$ In ieder geval lewe die chilias baje sterk uit die hoop en verwagting - iets wat baie gestimuleer word deur die huidige onoplosbaarheid van diê krisis. Die christelike hoop en verwagting moet seker nie net Nieu-Testamenties opgebou word nie; die O.T. moet beslis hierby verdiskonteer word.

\subsection{Onduidelikheid t.o.v. sekere aspekte van die eindgebeure}

Die onduidelikheid raak o.a. die gereformeerdes se ongenuanseerde gebruik van Israel waaroor later meer. Verder is daar by ons nie genoeg duidelikheid oor die antichris nie, terwyl die chiliaste miskien weer te ver gaan deur as volg te konkludeer: Israel keer as verharde volk terug na hulle land en rig dan self die gruwel van verwoesting op in die herboude tempel en bring, juis in hulle verhardheid, die antichris voort en wel uit die geslag van Dan, gesien die profesie in Gen. 49 en die weglating van Dan uit Openb. 7. volgens word die benaming ,eerste opstanding” in Openb. 20 veral heilshistories benader vanwë̈ hulle bepaalde (in sekere opsigte sikliese geskiedbeskouing: begin en eindig by Israel) terwyl dié gedeelte nie net heilshistories is nie, maar veral heilsordelik, Joh. $6: 47$. (Sien verder by voetnotas 19 en 20). Verder maak hulle baie erns met die noue verbondenheid tussen mens (resp. Godsvolk) en die skepping (resp. die land). As die mens weer 'n 1000 jaar rus en vrede het, moet die skepping dit ook hê, vgl. Jes. 11. As 'n mens die seëninge van die tegniek buite rekening laat, is dit inderdaad moeilik om juis die vervulling van hierdie gedeelte na die hemel- 
vaart te sien. Hierdie is egter nie net 'n probleem vir die chiliaste nie maar 'n groot probleem vir haas die hele moderne teologie, nl. die polarisasie van God en wêreld en die verdemonisering van die tegniek. Wesenlik hoort wat met die mens gebeur en met die res van die skepping, ten nouste bymekaar. Die regte oplossing hier bly moeilik, tog is dit merkwaardig dat die tegniek, veral in sy opset, 'n westerse produk, eers moontlik geword het nadat die christelike geloof die heidense denkwêreld van Europa deurbreek het. Maar in plaas daarvan om dit op te merk en die seëninge van die tegniek, wil ons al meer die tegniek verdemoniseer (is ons reg om so te maak?) en geloof en wetenskap teen mekaar afspeel. Nogtans bly die feit dat die kosmiese vreugde van die vredestyd in die natuuropenbaring val en ons die vervulling dus ook daar moet gaan soek, gekoppel aan die verandering by die mense, nl. opgestaan in Christus. Ek dink ons moet die tegniek meer positief benader en kyk net hoe kan gelowiges dan die aarde omskep in vreugde i.p.v. besoedeling. Miskien lê die fout al by die uitgangspunt: die aarde tem i.p.v. die skepping stem op die lied van die herskepping in Christus, Rom. 8. Die besoedelingsvraagstuk wat ook eschatologiese afmetings aanneem, hang nou saam met die oorgang van die christelike kultuur-era na die post-christendom! Tog bly hier probleme. Wat wel opmerklik is, is die volgende progressiewe uitbreiding: Noag-verteenwoordigers uit die diereryk; Abraham - 'n ganse landstreek in sy geheel; sal dan by die volheid in Christus weer net teruggekeer word na die beperkte van Abraham, nl. een land, terwyl die evangelie van die koninkryk wêreldwyd verkondig moet word? Dus die kern: in Christus stagnering van die Abrahamitiese belofte na sy O.T. vervulling in Israel? of voortgaande, wêreldwye progressiewe uitbreiding in Christus, die Koning? (Rom. 8; Filip. 2; Hand. 2 : 39).

Ten slotte onder hierdie punt nog net die volgende problematiek: wederkoms-vrede: wanneer en hoe? Is daar 'n wederkoms voor die 1000 jaar en word die gelowiges dan saam met Hom weggevoer in die lug en is daar dan later die finale wederkoms? In sake die aantal en die tydstip praat Jesus altyd van sy wederkoms in die enkelvoud en daarom sit chiliaste hier met 'n probleem by Sag. $12: 10$ en Openb. $1: 7 .^{10}$ Die antwoord lê hier seker in Openb. waar Christus sy koms positief in enkelvoud aankondig by die uitstorting van die sesde plaag - sien verder by die behandeling van Openb. T.o.v. die vrede-wederkoms, vrede gekoppel aan die wederkoms, word by die chiliaste die O.T. vredeskategorie, nl. Salomonies, nie deurbreek in Christus nie terwyl die N.T. tog volheidsklanke laat hoor oor die vrede in allesomvattende sin en blywend in Christus, Fil. 4: 7; Efes. $6: 15$, ens. terwyl dit inderdaad 'n vraag is of vrede gekoppel kan word, 'n vredestyd, aan die wederkoms, bv. in die lig van Matt. $26: 64$, ens. Openb. 16 en ook verder die res van die N.T. getuienis betrek die wederkoms op die laaste en groot oordeelsdag (Matt. 24-25). Struikelblokke wat die chilias hier moet oorwin, is O.T. tipologie, tı 


\section{Formulering van 'n antwoord}

By die formulering van 'n antwoord op die chiliasme moet ons, na my mening, rekenskap gee van drie groot kernsake. Dit is nl.:

a. die vraag na die verhouding O.T.-N.T.;

b. 'n openbaringshistoriese verantwoording van wie is Israel;

c. ' $n$ kanoniese indeling en behandeling van Openbaring. Hieruit sal dan duidelik word dat die chiliasme in Geref. kringe meer 'n hermeneutiese dwaling is as 'n leerstellige dwaling.

\subsection{Verantwoording van die vrae}

4.1.1. Die vraag na die verhouding O.T.-N.T. raak die hele problematiek van a. wie is Israel en wat is sy betekenis in die Bybel? b. die profesie en die vervulling daarvan en die legitimiteit van die „onvervulde" profesie; c. die posisie van Israel by heilshistoriese hoogtepunte.

4.1.2. Die openbaringshistoriese verantwoording van wie is Israel sal duidelike riglyne gee op a. weer eens die vraag wie Israel is; b. riglyne vir prediking uit O.T.-stof (dikwels word hier eksemplarisme en tipologie ter hand geneem i.p.v. die voortgang van die openbaring na Christus toe); c. riglyne rakende die probleem Israel-Kerk: het Israel oorgegaan in die kerk; staan Israel nog buite die kerk (die dispensasionaliste se siening van die kerk nou as bedeling van die heidene); die opset van die sending onder die Jode, ens.

4.1.3. Die kanoniese indeling en behandeling van die boek Openbaring. Dit word deur die chiliaste ontken dat hulle leer net gebou is op die Openb.-boek, veral $20: 1-11$. Hierdie gedeelte is volgens hulle nie die grondbewys van die milennium nie. Diskussie op hierdie punt eindig net in sirkelredenasies want steeds bly die vraag: uit watter hoek benader jy Openb.? Is dit net uit die feit dat dit apokaliptiese literatuur is (is dit net die vervolg op Daniël uit die O.T.)? In watter sin van die woord bied Openb. openbaringsgeskiedenis, ens. Die regte benadering van Openb. berus nie op dogmatiese vooropstellings nie (chiliaste en gereformeerdes is beide hieraan skuldig!) maar die regte benadering berus m.i. eerder op 'n gereformeerde kanoniese indeling: dan kom die boek self aan die woord en dit kan, soos u later sal sien, eksegese van betrokke gedeeltes diep beïnvloed!

\subsection{Die verhouding O.T.-N.T.}

U ken die baie bekende oplossings van hierdie diepgaande probleem: profesie en vervulling; blomknop en volgroeide blom, ens. Dis handige kitsoplossings waarin egter nie die hele saak ter sprake kom nie. M.a.w. dié vlae dek nie die lading nie. ${ }^{12}$

Die oplossing profesie-vervulling is onvolledig want baie pro. fesië is in die O.T. reeds vervul. As die profesie en die ganse strekking van die O.T. op Christus betrek word (Hebr. $1: 1$ ), dus Christusaankondiging en vervulling hiervan, dan is dié skema seker reg hoewel 'n mens somtyds dan regtig diep, miskien te diep sal moet 
grawe om te bewys dat Christus die eerste Bedoelde is van die betrokke profesie of gebeurtenis. M.a.w. dis niks anders as 'n knellende keurslyf waarby die historiese in die O.T. onderwaardeer kan word. Dan begin die aanklag van vergeesteliking aan geref. adres inderdaad eksegetiese regsgronde verdien!

Dieselfde argument is amper mutatis mutandis ook van toepassing op die knop en blom-skema. Die verdienste is hier dat daar wel meer rekenskap geree word van historiese voortgang maar die konsekwensies is bv. dat die priesterskap van Aäron en Melchisédek kongruent verklaar word: die een is net meer as die ander maar basies het daar niks verander nie.

Tog is daar beslis nuwe dinge wat Nieu-Testamenties nuut is en ander sake wat verouderd is en nie in die N.T. tot verdere ontplooiing kom nie, maar op die agtergrond raak en verdwyn of oud word, Hebr. $8: 13$. Weer die voorbeeld van die priesterskap: die Aäronitiese priesterskap oor die verbondsvolk is tog anders as die Melchisédek-priesterskap van Christus oor sý volk. T.o.v. die priesterskap in verhouding tot die volk, is die nuwe, die volstrek nuwe vir die volk van God dat die Hoëpriester tegelyk Koning is. Melchisédek is nie die verlengstuk van Aäron tot sy logiese kensekwensies nie maar in die verhouding priester-volk het daar beslis nuwe dinge gekom. Christus se priesterskap is nie alleen heerliker en voller as dié van Aäron nie soos die blom voller en heerliker as die knop, maar op ingrypende punte is dit ook anders. Daar is meer voorbeelde. Om egter dié skemas te handhaaf, moet die teoloog reduseer tot: wat is eintlik die wesenlike van die O.T. wat in die N.T. uitgebrei en vervul word. Dit kan lei tot die gevaar van wese en verpakking, en ek meen dat die uiterstes waartoe dit gedryf word vandag, bv. in Holland, o.a. terugvoerbaar is na die skematiese sienings van die verhouding O.T.-N.T. en dat die geref. teologie in bv. Kuitert en Wiersinga, bo en behalwe die hardnekkige volharding van die Chiliasme in die geref. kerk, 'n onbetaalde rekening ontvang!

Streng gesproke wonder ek of die verhouding O.T.-N.T. waarlik vasgelê kan word in 'n tref-en-trapformule soos bogenoemdes! Dié verhouding is nie 'n formule nie want in die Bybel spreek God en die mens luister. God verander nie en sy heilswerk gaan voort maar die mens is die veranderlike, eintlik vanweë die sonde, die onstabiele. Dis trouens ook so geweldig van die Skrif: dat God Hom aan mense openbaar. Dus die onveranderlike God en sy openbaring vertoon 'n stygende lyn omdat die mens nie alles op een keer kan inneem nie. Maar hierteenoor juis die mens wat die onstabiele is. So het die openbaring van God 'n geskiedenis maar die mens het ook 'n geskiedenis, bv. die roeping van Abraham tot die wegvoering in ballingskap, en hierdie onstabiele is deel van die openbaring soos ons hom het. Daarom is dit vir my 'n prinsipiële vraag of die verhouding tussen O.T. en N.T. in ' $n$ formule vasgelê kan word. Hierdie paragraaf wil ek afsluit, nie deur 'n kitsoplossing te gee nie - dis 'n studie afsonderlik - maar deur positief die stelling te maak: die verhouding O.T.-N.T. kan nie en mag nie in 'n formule vasgelê word of 
gedefinieer word nie. Gevare en nadele hieraan verbonde is meer as die voordele.

\subsection{Openbaringshistoriese verantwoording: wie is Israel?}

Hier wil ek slegs hoofpunte aanstip. U ken die stelling: Israel is die uitverkore volk van God en sommige mense meen dat Israel dit vandag nog is en andere meen dat dié uitverkore posisie vervul is in die geboorte van Christus en verval het by hulle verwerping van die Messias. $U$ sien: 'n verskeidenheid van menings en vereenselwiging van volksroeping en uitverkiesing tot die ewige lewe. Israel die volk van God. Wat was die posisie; wat is dit vandag?

Die volk van die belofte. Israel begin nie by Jakob nie maar by Abraham, Gen. 15 : 5. Voorop staan dus nie die feit van die 12 stamme nie (hou dit in gedagte by Openb. $7: 1-8$ ), maar die belofte, die verbond, die geloof op grond van die verkiesing. Daarom oor die vraag wie Israel is, gaan Paulus in Rom. $9: 6$ v.v. sy betoog fundeer in Abraham, juis om die verbond en die verkiesing te demonstreer. Die volk van die Here is primêr die volk van die belofte, nie die vleeslike verbondenheid aan Abraham nie. Hierdie uitverkorenes, kinders van die belofte, hulle is in die O.T. eintlik Israel, vgl. vers 6: hulle is nie almal Israel wat uit Israel is nie, en verder Rom. 11: 7: wat Israel soek, dit het hy nie verkry nie; maar die uitverkorenes het dit verkry en die ander is verhard. Paulus maak dus hier 'n onderskeid tussen Israel en die uitverkorenes. Almal word wel Israel genoem, maar hulle is nie Israel nie, want Israel is in der waarheid net die uitverkorenes. Ons kan dus rofweg onderskei tussen Israel as volksverband en Israel as geloofsverband. Openbarings-histories is die geskiedenis van Israel baie interessant en hiervan nou net flitsende hoofpunte:

4.3.1. Die verbondsteken was die besnydenis. By die uittog uit Israel was alle mans besny, Jos. 5 : 5. Behalwe Josua en Kaleb was verder die hele volk wat Kanaän ingetrek het, onbesnede, en nou is dit baie opvallend om te sien wanneer die verbondsteken toegeken word: nie in die woestyn nie maar op strategies die mees kritieke stadium: net na die intog in die beloofde land. Ons weet ook waarom eers in Kanaän besny. Onder die strawwende hand van die Here moes die ou geslag in die woestyn sterf vanweë hulle geloof en ongehoorsaamheid, Hebr. 3. Die volk het die verbond verag met hulle Egipte-verlange en dan word die volk eers weer besny as hulle in die beloofde land is, as God sy belofte aan Abraham gestand gedoen het. M.a.w. die voortsetting van die verbond is nie kragtens vleeslike verbondenheid aan Abraham nie, maar net kragtens God se verbondstrou! Dat die intrekkers in Kanaän Israel is, is alleen 'n genadewonder, want God doen sy belofte aan Abraham gestand.

4.3.2. Die volgende opsienbarende punt wat ek wil noem is die skeuring van die ryk na Salomo. Vanweë die afgodery van Salomo, 1 Kon. 11 : 11, het God die koningskap van Salomo afgeskeur en 
aan Jerobeam gegee. Opmerklik: die koningskap, en Christus sit op die troon van Dawid! Christus volg dus nie die laaste koning, nl. Sedekia op nie, maar Hy volg Dawid direk op!13 Verder, Jerobeam kry 10 stamme, 1 Kon. $11: 31$, en die ryk van Jerobeam het verder konsekwent die naam Israel. God sê met soveel woorde in Kon. 11 : 37 dat Hy Israel aan Jerobeam sal gee. Dus: koningskap en Israel losgeskeur van Salomo. En verder: een stam word aan Rehabeam gegee ter wille van Dawid en Jerusalem wat $E k$ verkies het. In die geskiedenis van Juda word later telkens teruggekom na Dawid en Jerusalem wat $E k$ verkies het. Israel en koningskap van Salomo afgeskeur maar een stam bly behoue ter wille van Dawid. Kortliks kom dit hierop neer dat wat in die volk van die Here behoue bly as volk, alleen ter wille van die verkiesing is, die belofte van God, God se verbond met Dawid. Die volle koningskap, met die koning uit die stam Juda, begin dus by Dawid en hou eintlik voorlopig daar op en word eers weer hervat in Christus wat op die troon van sy vader Dawid sit. En verder: die verband koningskap-onderdaan bestaan in die volle sin van die woord slegs by Dawid en ook dit word weer hervat in Christus as die Seun van Dawid en daarby die tweede Adam. Wat ná Dawid kom en dan spesifiek die verband koningskap-Israel, dit val weg in ballingskap, 2 Kon. 17, vanweë die sonde, afgodery en die toorn van God. Die lyn van versoening, die Aäronitiese priesterskap, is voortaan in Juda en nie in Israel nie bedien, want Jerobeam het die Leviete weggejaag en selfs sy eie priesters aangestel. Dis dan onskriftuurlik om ongenuanseerd van Israel te praat - Paulus wys ons daarop in Rom. 11 vanaf vers 6 .

Opvallend is egter dat die chiliaste die toekoms van die eerste Israel wat in die woestyn omgekom het, verswyg, maar die toekoms van die tweede Israel nl. dié onder Jerobeam wat per slot van rekening ook maar dieselfde pad geloop het as die eerste Israel, dié toekoms word grootliks uitgebou volgens hulle profesieverklarings. So word die openbaringshistoriese posisie van Juda, nl. God se verbondstrou aan Dawid en Abraham ter wille van Christus, heeltemal deur hulle onderskat en uit verband geruk. Ek hoop erter dat dit duidelik is dat dit onmoontlik is om die profesie te verklaar, suiwer te verklaar, volgens 'n ongenuanseerde Israel-begrip. En verder: 'n genuanseerde Israel op grond van openbaringshistoriese getuienis is iets anders as 'n vergeestelikte godsvolkbegrip waarvan geref. teoloë dikwels beskuldig word en somtyds ook tereg. Hierby wil ek volstaan in die hoop dat bogestelde agtergrond ons sal lei na 'n meer konkrete kennis van wie Israel is. Net dit: die geslote verhouding (nie waterdig nie, vgl. die opname van Ragab in Israel) Godsvolk en volksverband, word op Pinkster openlik deurbreek deur die tale-wonder en dis gefundeer in Christus se Middelaarswerk, Ef. 2.

4.3.3. Nog 'n enkele woord oor die heilshistoriese oorgang: nie die wet nie (die geskiedenis van Juda) maar die genade (Rom. 7-8). Hierdie oorgang, ${ }^{14}$ gefundeer in die werk van Christus (Rom. $8: 3-4$ ), is nou ons indikatief-imperatief stand van sake, Rom. 6; dis reeds voorspel deur die profete, bv. Jer. $31: 31-40$, maar veral vers 
31-33 wat verder Nieu-Testamenties gekommentariër word in Hebr. 10 : 15-18. (Nota: vers 31 noem afsonderlik huis van Juda en huis van Israel; vers 33 noem net die huis van Israel - Juda word hier verswyg - terwyl Hebr. dit van toepassing maak op die Nuwe Testament situasie. Dit wil ek as volg verklaar: die dubbele aanspraak in vers 31 is die adres van die profesie; Israel in vers 33 is die aanspraak van die Godsvolk, die ware Israel, en Hebr. wys op die vervullin? hiervan: die volle Israel in die Nieu-Testamentiese tydvak. (Slot volg)

\author{
D. H. P. Wijnbeek, Lindley. \\ (Gelewer voor G.T.V. van die O.V.S.)
}

\title{
VERWYSINGS
}

1 Vgl. die sterk apologetiese strekking van die dun boekie van ds. C. W. M. du Toit: Die koning,kap van Christus in sy verhouding tot die Koninkryk van God.

2 Vgl. die sterk uitsprake van hoofstuk 17, die preek oor Sagaria 14, in: Die naggesigte en profesië van Sagaria, deur ds. C. W. M. du Toit, p. 66-70.

3 Hier ie bewering berus nie op skriftelike gegewens nie aangesien dit nie beskikbaar is nic. Dis egter my eie waarneming uit baic gesprekke met die aanhangers van die leer en uit gereelde bywoning van hulle Bybclstudie byeenkomste.

4 Fk meen dat ons die neiging tot polarisasie en die beëindiging daarvan in die teologie deels aan hierdie leemte kan koppel. Hierdie opmerking raak ook die volgende beswaar.

5 Wat ek met hierdie stelling beoog, is dat in die profesie nie alleen die kıuis van Christus verkondig word nie, maar ook duidelik gewys word op $:$ ie konsekwensies hiervan, nie net op die nuwe aarde nie, maar reeds in hierdie aardse tyd, nl. onder die heerskappy van Christus aan die regterhand van God. Die term Christo-sentries bedoel die kruis van Christus en die volle konsekwensies hiervan. Die term Christo-monisties bedoel dat die profesie net wil sê dat Christus sal kom en die volkome offer aan die kruis gaan bring. Hierdie term bedoel ek nie met die Barthiaanse lading nie. Hierdie arm Christusprediking het ek nie alleen aangetref by geref, preke uit profetiese stof nie maar ook by die preiliking uit ander skrifgedeeltes.

6 Vgl. die treffende eksegese van Lukas $23: 34$ by dr. K. Schilder: Christus in zijn lijden, deel 3, Kampen, 1952 .

7 König, A.: Jesus Christus die Eschatos, N.G. Kerk-boekhandel, Pretoria, 1970. R.G.N.-reeks nr. 7.

8 Die verwarring en versigtigheid van gedagtes by sommige artikels in Gereformeerd Weekblad na die Jom-Kippoer-oorlog was vir my wat dit betref baie opvallend.

$9 \mathrm{Du}$ Toit, C. W. M.: Toekomstige wèreldgebeure, V.C.G. kerk, Frankfort, 1948, p. 139-141. Teenoor hierdie redenasie wat Du Toit beskou as gebruikmaking van die reël om Skrif met Skrif te vergelyk, p. 139, word Dan deur Moses in Deut. 33 : 22 weer met 'n jong leeu vergelyk wat uit Basan uitspring (Gen. 49: Juda is 'n jong leeu; van die roof af het jy opgeklim!). Teenoor die weglating van Dan uit Openb. 7 word aan Dan 
in Eseg. 48 : 1, by die verdeling van die herstelde land - wat volgens chiliaste verwys na dieselfde vrederyk! - wel aan Dan 'n deel in die land gegee! Hoe nou?

10 Tog wil die chiliaste in die Geref. Kerk nie van 'n dubbele wederkoms weet nie. Baie duidelik word die moontlikheid van 'n dubbele wederkoms afgewys in ' $n$ artikel in die Getuie, Okt. 1954. Baie sektariese groepe egter staan op die standpunt van 'n dubbele wederkoms. Hierdie saak word baie mooi behandel deur Oswald T. Allis in sy boek: Prophecy and the church; The Presbyterian and Reformed Publishing Company, Philadelphia, 1964.

11 Interessant is by die chiliaste die volgorde van die laaste groot gebeurtenisse. In die reeds aangehaalde artikel uit Die Getuie van 1954 is die volgorde as volg: die groot verdrukking en die optrede van die anti-chris; die wederkoms wat 'n einde maak aan hierdie dinge, en die vredestyd as vrug van die wederkoms; dan die laaste groot opstand en die laaste oordeel. Aanleiding tot hierdie volgorde is m.i. nie soos hulle beweer sekere tekste uit die O.T., nl. veral Sag. $12: 9-10$ en Jes. $27: 13$ nie, maar basies in die onderskatting van die ,reeds”, dat die koninkryk van God gekom het en komende is, en tweedens dic skeiding van die Koningskap en Priesterskap van Christus. Volgens hulle is Christus nog net priesterlik besig maar eers in die vredestyd, dan regeer Hy as íoning. Vgl. veral die reeds genoemde boekie van $\mathrm{Du}$ Toit oor die koningskap van Christus.

12 Vgl. Du Toit, S.: Openbaringsgeskiedenis van die Ou Testament, Pro Rege-Pers Beperk, Potchefstroom, 1969-1, p. 26. Die Ou Testament is nie net latent en die nuwe net patent nie want daar is nog bepaalde sake in die Nuwe Testament wat nog moet plaasvind, bv. die wederkoms. Treffend in hierdie verband ook cile woorde van Hebr. $8: 13$ : oud word, verouder, en: naby die verdwyning.

13 Christus vertoon wel baie tekens van Salomo se koningskap, bv. die vredestyd, maar waar by Dawid en Salomo oorwinning en vredesheerskappy verdeel is oor die heerskappy van respektiewelik die 2 konings, val die 2 aspekte by Christus saam in die werk van die EEN: Jesus Christus.

14 Ek noem dit spesifiek oorgang en nie deurgang nie want die wet was kragteloos vanweë die vlees. Die vlees maak deurgang onmoontlik. Die knop- en blomskema is egter gebaseer op die deurgang-gedagte wat $m . i$. op hierdie punt een van sy opmerklike tekorte openbaar. 